\title{
Mesoporous microspheres of nickel-based layered hydroxides by aerosol-assisted self-assembly using crystalline nano-building blocks
}

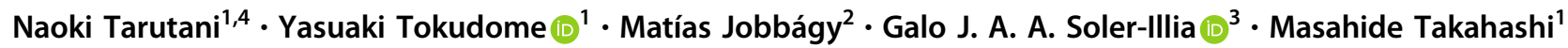

Received: 15 February 2018 / Accepted: 5 September 2018

(c) Springer Science+Business Media, LLC, part of Springer Nature 2018

\begin{abstract}
Structural control in micro- and nanometer scales is necessary to design highly functional materials. Crystalline mesoporous microspheres (MMSs) are expected to improve electrochemical, catalytic, and adsorption performances. In this study, we focused on the preparation of templated MMSs of nickel-based layered hydroxides by using pre-crystallized nano-building blocks (NBBs). Layered nickel hydroxide nanoparticles were prepared through an epoxide-mediated alkalinization process and used as NBBs to construct microspheres. The spherical particles in micrometer scale were synthesized by an aerosolassisted assembly of the NBBs dispersed in a solvent, in the presence of supramolecular templates. It was found that controlling the crystallization as well as the surface philicity permits to yield the NBBs with an adequately small size and interparticle interactions that generate self-assembled MMSs akin to those obtained in NBB-based mesoporous thin films. The preparation technique demonstrated here is highly versatile; templated MMSs with various chemical compositions of nickel-based layered double hydroxides were successfully obtained.
\end{abstract}

\section{Graphical Abstract}

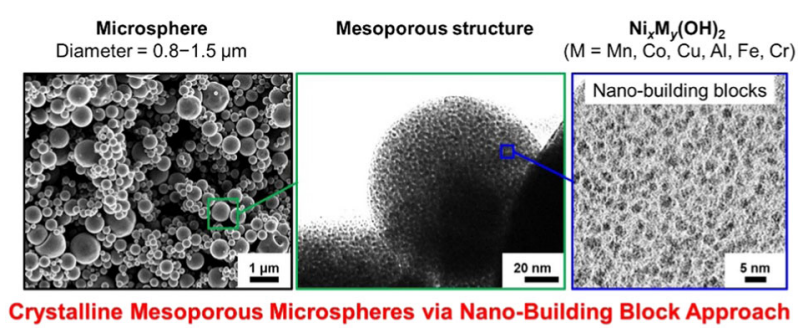

\begin{abstract}
Electronic supplementary material The online version of this article (https://doi.org/10.1007/s10971-018-4810-z) contains supplementary material, which is available to authorized users.
\end{abstract}

\footnotetext{
Yasuaki Tokudome tokudome@mtr.osakafu-u.ac.jp

1 Department of Materials Science, Graduate School of Engineering, Osaka Prefecture University, Sakai, Osaka 599-8531, Japan

2 INQUIMAE-CONICET, Facultad Ciencias Exactas y Naturales, Universidad de Buenos Aires, Buenos Aires C1428EHA, Argentina
}

3 Instituto de Nanosistemas, Universidad Nacional de General San Martín-CONICET, Av. 25 de Mayo y Francia, San Martín 1650, Buenos Aires, Argentina

4 Present address: Department of Chemical Science and Technology, Faculty of Bioscience and Applied Chemistry, Hosei University, Koganei, Tokyo 184-8584, Japan 


\section{Highlights}

- Synthesis of mesoporous microspheres composed of crystalline layered nickel hydroxide and layered double hydroxides is demonstrated.

- Spray-drying was applied to colloidal suspensions of crystalline nano-building blocks for the synthesis.

- Controlling the crystallization and surface philicity are important factors for the successful self-assembly.

- The preparation technique demonstrated here is highly versatile and can be extended to various systems.

Keywords Crystalline mesoporous microspheres $\cdot$ Nano-building blocks $\cdot$ Layered nickel hydroxides $\cdot$ Layered double hydroxides $\cdot$ Epoxide-mediated alkalinization

\section{Introduction}

The design and development of micro- and nanometerscale structures have attracted attention not only in fundamental aspects of materials science, but also in many applications. Mesoporous microspheres (MMSs) exhibit several unique/beneficial features, which make them highly attractive for biomedical, sensing, and photocatalytic and adsorbent applications [1-5]. The spherical shape of MMS improves the flowability of particles, the long-term stability as suspensions [6], and versatile processability for coatings. In addition, templated mesoporous structures of MMS provide a high specific surface area, large pore volume, and large number of accessible reactive surface sites, which enable them to be used as very efficient nano-reactors, and impart size selectivity of guest species due to well-defined regular pore size [7, 8]. These features of MMS make them highly useful and attractive for applications, such as electrocatalysts and flow capacitors [9, 10].

Although crystalline mesoporous materials are strongly demanded for applications, such as photocatalysts, capacitors, and adsorbents [11, 12], MMSs are generally obtained as amorphous materials showing lower performance compared with crystalline counterparts [13, 14]. The crystallization of amorphous MMS with preserving the original mesoporous structure is a considerable challenge. Posttreatments, such as heating, have been employed for the crystallization of MMS [15]; however, the crystallization of amorphous phases by post-treatments typically collapses the mesoporous structures and disturbs micrometer-scale shapes in some cases. In addition, MMSs of non-oxide crystals, such as hydroxides, sulfides, and nitrides, are difficult to prepare through conventional methods due to the instability of these materials at high temperature in an air atmosphere. Alternative synthetic routes of the crystalline MMS are required toward a more versatile material design. One promising approach is the use of preformed nano-building blocks (NBBs) that can be self- and co-assembled with supramolecular templates [16-18].

We here demonstrate an approach using precrystallized NBBs for the fabrication of MMS materials with crystalline inorganic walls. Colloids of nanocrystalline layered nickel hydroxides, $\alpha-\mathrm{Ni}(\mathrm{OH})_{2}$, were prepared through an epoxide-mediated alkalinization in the presence of carboxylic acids. The resultant colloidal nanocrystals were used as NBBs to construct MMS through an aerosol-assisted self-assembly process using a spray-dryer [19]. It was found that controlling the crystallization as well as the surface philicity permits to yield the NBB with an adequately small size and interparticle interactions that generate self-assembled MMSs. The preparation technique demonstrated here is highly versatile and MMSs of various chemical compositions of layered double hydroxides (LDHs), with tunable diameter and shapes, were successfully designed.

\section{Experimental}

\subsection{Chemicals}

Aluminum chloride hexahydrate $\left(\mathrm{AlCl}_{3} \cdot 6 \mathrm{H}_{2} \mathrm{O}, 98.0 \%\right)$, chromium(III) chloride hexahydrate $\left(\mathrm{CrCl}_{3} \cdot 6 \mathrm{H}_{2} \mathrm{O}, 99.5 \%\right)$, manganese(II) chloride tetrahydrate $\left(\mathrm{MnCl}_{2} \cdot 4 \mathrm{H}_{2} \mathrm{O}, 99.0 \%\right)$, iron(III) chloride hexahydrate $\left(\mathrm{FeCl}_{3} \cdot 6 \mathrm{H}_{2} \mathrm{O}, 99 \%\right)$, cobalt chloride hexahydrate $\left(\mathrm{CoCl}_{2} \cdot 6 \mathrm{H}_{2} \mathrm{O}, 99.0 \%\right)$, nickel chloride hexahydrate $\left(\mathrm{NiCl}_{2} \cdot 6 \mathrm{H}_{2} \mathrm{O}, 98.0 \%\right)$, copper chloride dihydrate $\left(\mathrm{CuCl}_{2} \cdot 2 \mathrm{H}_{2} \mathrm{O}, 99.0 \%\right)$, acrylic acid $(99 \%)$, glutaric acid (98\%), ethanol (99.5\%), propylene oxide (>99\%), and Pluronic F127 block copolymer (F127) (MW 12.6 kDa) were used as received. Acrylic acid, propylene oxide, and F127 were purchased from Sigma-Aldrich Co. All other reagents were purchased from Wako Pure Chemicals Industries, Ltd. Ultrapure water of $18.2 \mathrm{M} \Omega \mathrm{cm}$ resistivity was used in all experiments.

\subsection{Synthesis of a-Ni(OH $)_{2}$ mesoporous microspheres}

$\mathrm{NiCl}_{2} \cdot 6 \mathrm{H}_{2} \mathrm{O}(0.5 \mathrm{mmol})$ and glutaric acid $(0.5 \mathrm{mmol})$ were dissolved in ethanol $(17.2 \mathrm{mmol})$, and propylene oxide $(7.5 \mathrm{mmol})$ was added to this solution under stirring. After stirring for $30 \mathrm{~s}$, the solution was left at $25^{\circ} \mathrm{C}$ 
for $1-8 \mathrm{~min}$. The reacting solution was diluted with 50 $\mathrm{mL}$ of water dissolving F127 $(2.5-15 \mu \mathrm{mol})$ and stirred for $1 \mathrm{~min}$. The obtained homogeneous sol was spraydried using a Buchi B-290 mini spray-dryer. The spray conditions are as follows: inlet air temperature of $150^{\circ} \mathrm{C}$, gas (air, $35 \pm 5 \mathrm{RH} \%$ ) flow rate of $246-742 \mathrm{~L} / \mathrm{h}$, and peristaltic pump speed of $6 \mathrm{~mL} / \mathrm{min}$. The dried powders were collected from a sample glass vessel and heat treated at $250{ }^{\circ} \mathrm{C}$ for $6 \mathrm{~h}$ with a ramp rate of $1{ }^{\circ} \mathrm{C} /$ min under an air atmosphere.

\subsection{Synthesis of Ni-M LDHs (M = Mn(II), Co(II), Cu(II), $\mathrm{Al}(\mathrm{III}), \mathrm{Fe}(\mathrm{III})$, and $\mathrm{Cr}(\mathrm{III}))$ mesoporous microspheres}

$\mathrm{NiCl}_{2} \cdot 6 \mathrm{H}_{2} \mathrm{O}(0.375 \mathrm{mmol}), \mathrm{MCl}_{m} \cdot n \mathrm{H}_{2} \mathrm{O}(\mathrm{M}=\mathrm{Mn}(\mathrm{II}), \mathrm{Co}$ (II), $\mathrm{Cu}(\mathrm{II}), \mathrm{Al}(\mathrm{III}), \mathrm{Fe}(\mathrm{III}), \mathrm{Cr}(\mathrm{III}), m=2-3$, and $n=2-$ 6) $(0.125 \mathrm{mmol})$, and acrylic acid $(1.0 \mathrm{mmol})$ were dissolved in ethanol (17.2 mmol), and propylene oxide (7.5 mmol) was added to this solution under stirring. After stirring for $30 \mathrm{~s}$, the solution was left to stand at $25^{\circ} \mathrm{C}$ for $60 \mathrm{~min}$. The reacting solution was diluted with $50 \mathrm{~mL}$ of water dissolving F127 $(2.5 \mu \mathrm{mol})$ and stirred for $1 \mathrm{~min}$. The obtained homogeneous sol was spray-dried with conditions of inlet air temperature of $150{ }^{\circ} \mathrm{C}$, gas (air, 35 $\pm 5 \mathrm{RH} \%$ ) flow rate of $473 \mathrm{~L} / \mathrm{h}$, and peristaltic pump speed of $6 \mathrm{~mL} / \mathrm{min}$. The dried powders were collected from a sample glass vessel and heat treated at $250{ }^{\circ} \mathrm{C}$ for $6 \mathrm{~h}$ with a ramp rate of $1^{\circ} \mathrm{C} / \mathrm{min}$ under an air atmosphere. The sample prepared through this process was described as $\mathrm{Ni}-\mathrm{M}$, where $\mathrm{M}$ is an incorporated metal element $(\mathrm{M}=$ $\mathrm{Mn}, \mathrm{Co}, \mathrm{Cu}, \mathrm{Al}, \mathrm{Fe}$, and $\mathrm{Cr}$ ).

\subsection{Characterization}

A scanning electron microscope (SEM) was employed to observe the morphologies and measure the diameter of the obtained MMSs $\left(D_{\mathrm{P}}\right)$. A transmission electron microscope (TEM; JEM-2000FX) and scanning TEM (STEM; JEM-2100F, JEOL, Japan) equipped with energy-dispersive spectroscopy (EDS) were employed at an operating voltage of $200 \mathrm{kV}$ to measure the diameter of NBB $\left(D_{\mathrm{NBB}}\right)$ and to observe the mesostructures of the MMSs. Powder X-ray diffraction (PXRD) using $\mathrm{Cu} \mathrm{K} \alpha$ radiation $(\lambda=0.15418 \mathrm{~nm})$ was used to characterize the crystalline phases. Small-angle X-ray scattering (SAXS) measurement was performed to characterize the diameter and mesostructures of MMSs with a lab-scale diffractometer (SmartLab, Rigaku, Japan) and the beamline of the Brazilian Synchrotron Light Laboratory (LNLS, Brazil D11A-SAXS1-18927). Details of the analyses of SAXS data are described in the Supporting Information.

\section{Results and discussion}

\subsection{Preparation of $\mathrm{a}-\mathrm{Ni}(\mathrm{OH})_{2}$ NBB colloids for the synthesis of mesoporous microspheres}

A solution containing nickel chloride and glutaric acid was used as a precursor solution; subsequent addition of propylene oxide induces alkalinization in the solution [20]. Figure 1 shows the time-dependent change of relative residual $\mathrm{Ni}$ ion amount and particle diameter after the addition of propylene oxide. Along with the reaction time, nanometer-sized particles formed and grew through the consumption of $\mathrm{Ni}$ ion, and gelation took place in $10 \mathrm{~min}$. A homogenous $\mathrm{pH}$ increase in minute-scale induces a high degree of supersaturation condition, which leads to the massive formation of nuclei and the subsequent growth of hydroxide nanocrystals [21]. Single-nm-sized particles can be obtained within $5 \mathrm{~min}$ of reaction. As we reported previously [22], the coordination of carboxylic acid to metal ions inhibits extensive crystal growth. For the proper selfassembly of block copolymer templates and NBBs toward mesoporous structure, NBBs are required to be smaller than the mesostructures (generally $<10 \mathrm{~nm}$ ), narrow in size distribution, and highly dispersible in hydrophilic solvents [23-26].

The reaction time, $t$, of 2 min was chosen as a condition to prepare MMS because $D_{\mathrm{NBB}}$ of $3.1 \mathrm{~nm}$ at $t=2 \mathrm{~min}$ (Fig. 1 ) is expected to be small enough for mesostructure formation. The PXRD pattern of spray-dried powder prepared from a solution of $t=2$ min showed several sharp peaks assigned to the remnant (unreacted) $\mathrm{NiCl}_{2} \cdot 2 \mathrm{H}_{2} \mathrm{O}$ and $\mathrm{F} 127$ [27] (Fig. 2a). Coarse $\mathrm{NiCl}_{2} \cdot 2 \mathrm{H}_{2} \mathrm{O}$ crystals (crystallite size: $21 \mathrm{~nm}$ ) were formed during drying because a large amount $(91 \%)$ of $\mathrm{Ni}$ ion remained in the solution at $t=2 \mathrm{~min}$. In addition, the segregation of crystalline F127 took place during spray-drying, though the concentration of F127 was

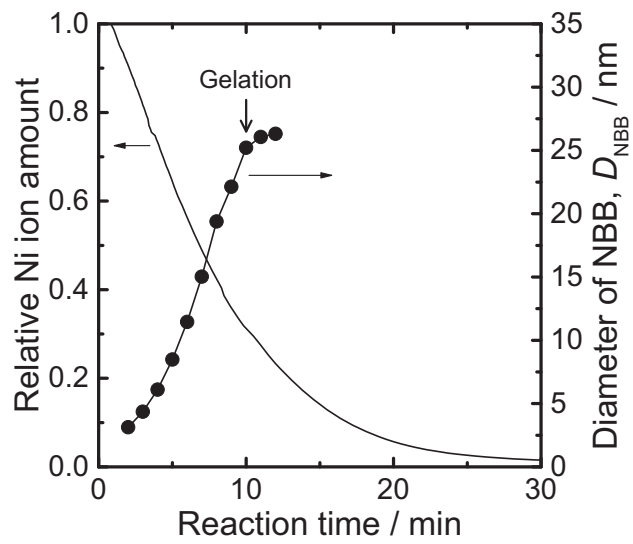

Fig. 1 Time dependence of relative $\mathrm{Ni}$ ion amount in the reacting solution (solid line) and the diameter of NBB calculated from in situ SAXS patterns (closed circle) 


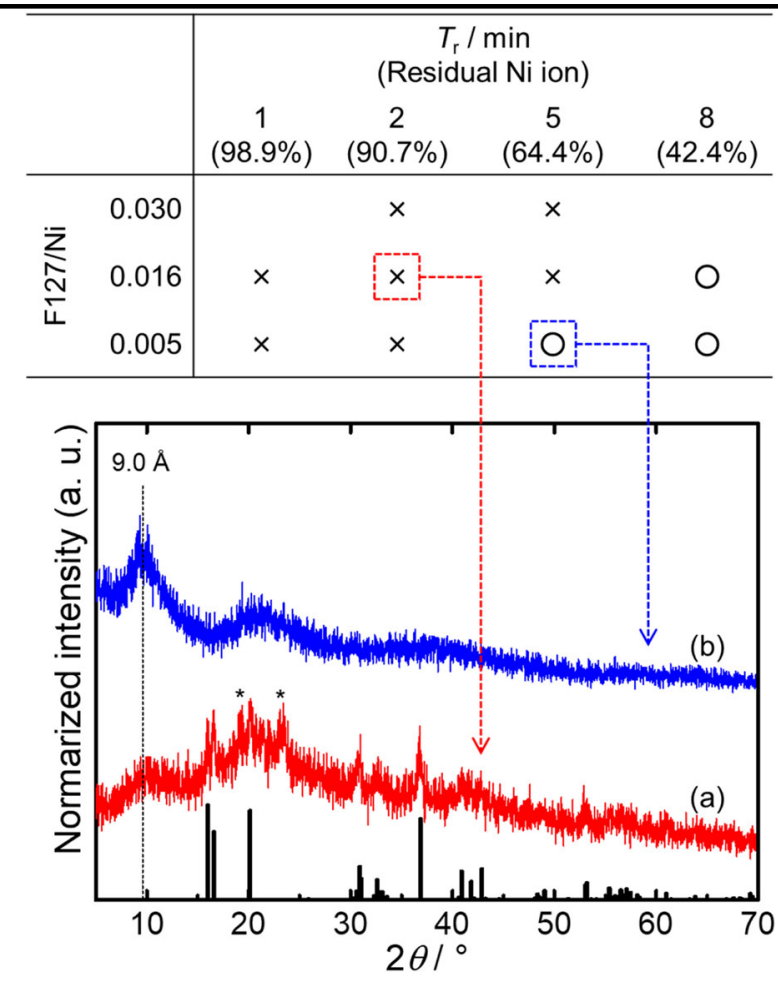

Fig. 2 Effects of reaction time, $t$, and molar ratio of $\mathrm{F} 127 / \mathrm{Ni}$ on the formed crystalline phase $\left(\mathrm{x}: \alpha-\mathrm{Ni}(\mathrm{OH})_{2}\right.$ with impurities and $\bigcirc$ : pure $\alpha$ $\left.\mathrm{Ni}(\mathrm{OH})_{2}\right)$. Corresponding PXRD patterns of spray-dried powder prepared with different conditions; a $t=2 \mathrm{~min}, \mathrm{~F} 127 / \mathrm{Ni}=0.016$, spray gas flow rate of $473 \mathrm{~L} / \mathrm{h}$, and $\mathbf{b} t=5 \mathrm{~min}, \mathrm{~F} 127 / \mathrm{Ni}=0.005$ spray gas flow rate of $742 \mathrm{~L} / \mathrm{h}$. (Black bar: $\mathrm{NiCl}_{2} \cdot 2 \mathrm{H}_{2} \mathrm{O}$ (\#72-0044); *: F127) the same as that reported for the conventional synthesis of mesoporous materials [28]. This may be explained by the relatively weak interaction of NBB with F127 compared with molecular precursors, such as alkoxides, resulting in macro-scale phase separation between NBB and F127. In order to inhibit the segregation of coarse $\mathrm{NiCl}_{2} \cdot 2 \mathrm{H}_{2} \mathrm{O}$ crystals and $\mathrm{F} 127$, the reaction time and $\mathrm{F} 127 / \mathrm{Ni}$ were tuned (see table in Fig. 2). Along with increasing $t$, $\mathrm{Ni}$ ion was consumed (Fig. 1) and the formation of $\mathrm{NiCl}_{2} \cdot 2 \mathrm{H}_{2} \mathrm{O}$ phase was minimized. Segregation of F127 was prevented by reducing the $\mathrm{F} 127 / \mathrm{Ni}$ ratio. At $t=5 \mathrm{~min}$ and $\mathrm{F} 127 / \mathrm{Ni}=$ 0.005 , spray-dried MMS shows PXRD pattern with a broad peak around at $2 \theta=10^{\circ}$, corresponding to the 001 plane of glutarate-intercalated $\alpha-\mathrm{Ni}(\mathrm{OH})_{2}(9.0 \AA)$ [22] (Fig. 2b). The $\alpha-\mathrm{Ni}(\mathrm{OH})_{2} \mathrm{NBB}$ colloids prepared under this condition were then diluted with an aqueous medium (used for spraydrying) and dropped on a TEM grid for their inspection (Fig. 3a). The spray-dried MMS showed spheroidal shape with $D_{\mathrm{P}}$ of $0.808 \mu \mathrm{m}$, with a standard deviation of $0.196 \mu \mathrm{m}$ (Fig. 3b). The large standard deviation indicates a polydispersity of particle diameter, which is a typical feature of spray-dried particles [28]. The NBBs composing MMS $\left(D_{\mathrm{NBB}}=4.89 \mathrm{~nm}\right)$ are smaller than the wall thickness of typical F127-templated mesoporous structures [29, 30], allowing co-assembly of the NBBs and F127 micelles (Fig. 3c). The MMS was then heat-treated at $250{ }^{\circ} \mathrm{C}$ for $6 \mathrm{~h}$ to remove the template F127. The PXRD pattern and SEM
Fig. 3 a TEM image of the NBB observed by drying the colloid on a TEM grid at $t=5 \mathrm{~min}$. Black arrows indicate NBBs with a spherical shape. b SEM images of spray-dried MMS prepared with a gas flow rate of $742 \mathrm{~L} / \mathrm{h}$. The condition of the solution before spray-drying was $t=5 \mathrm{~min}$ and $\mathrm{F} 127 / \mathrm{Ni}=0.005$. c Schematic illustration of spraydried MMS composed of $\mathrm{Ni}$ $(\mathrm{OH})_{2}$ NBBs and F127 micelles
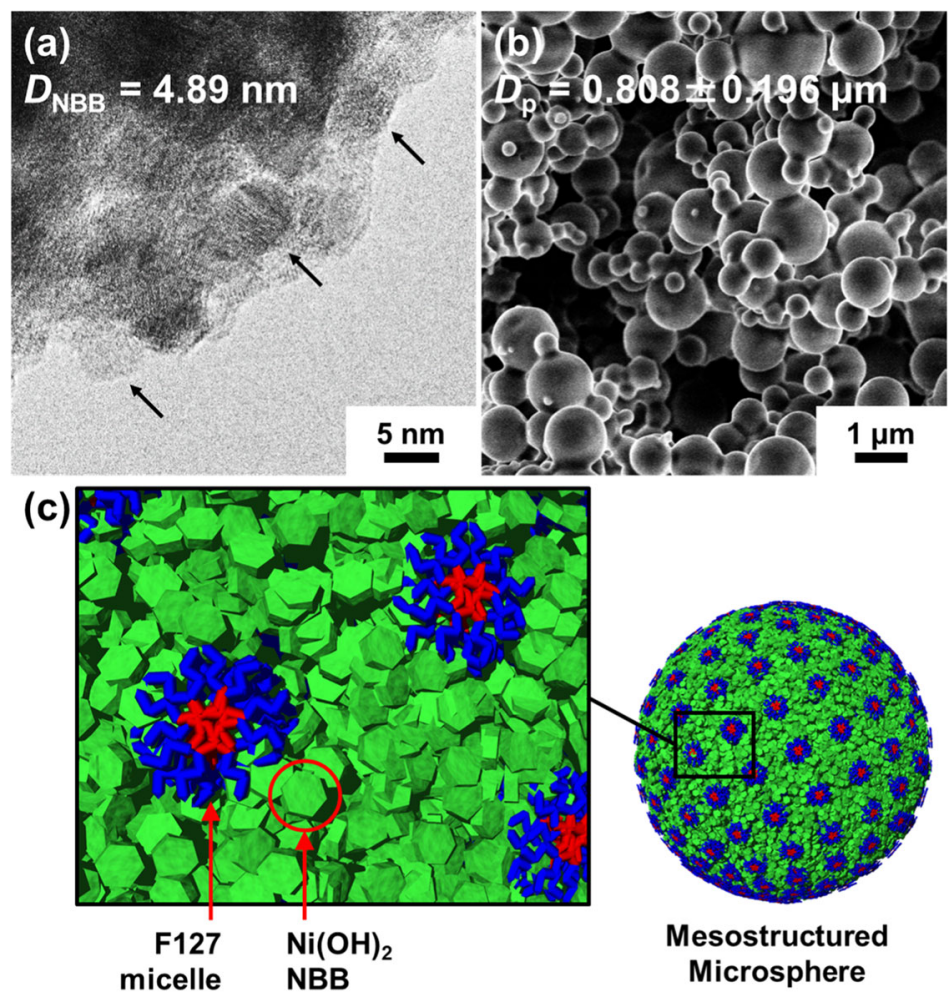
Fig. 4 a SAXS pattern and $b$ TEM image of heat-treated MMS prepared with a gas flow rate of $742 \mathrm{~L} / \mathrm{h}$. The condition of the solution before spray-drying was $t=5 \mathrm{~min}$ and $\mathrm{F} 127 / \mathrm{Ni}=$ 0.005

Fig. 5 SEM images of spraydried MMS prepared at different quenching time, $t_{\mathrm{q}}$, of a $1 \mathrm{~min}$ and $\mathbf{b} 3 \mathrm{~h}$. c SAXS patterns of spray-dried MMS prepared at $t_{\mathrm{q}}$ $=1 \mathrm{~min}$ (black) and $3 \mathrm{~h}$ (red). The arrow indicates the peaks corresponding to the selfassembled meso-periodic structure of NBB and F127 micelles. The condition of the solution before spray-drying was $t=5 \mathrm{~min}$ and $\mathrm{F} 127 / \mathrm{Ni}=0.005$
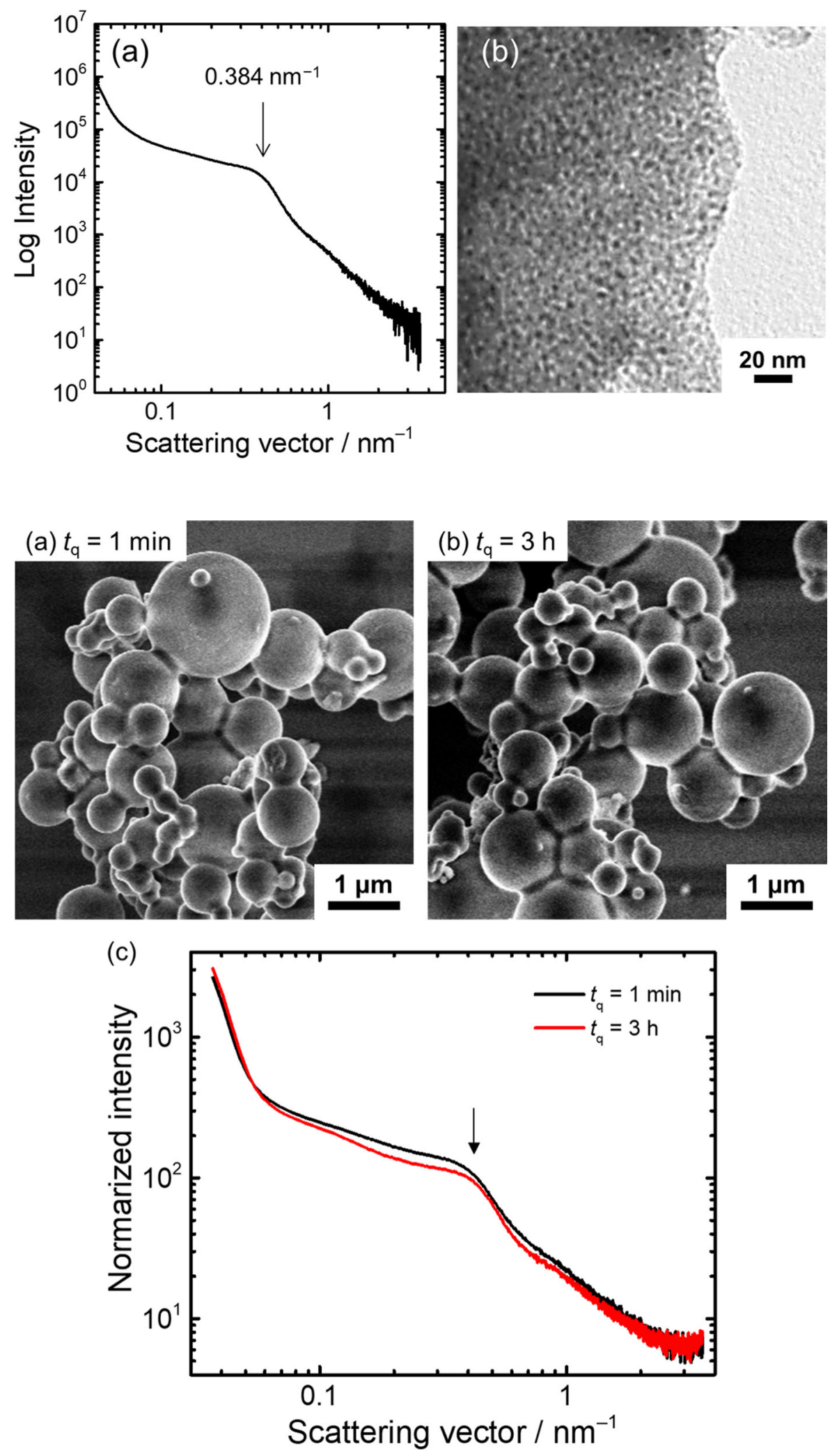

image of heat-treated MMS are comparable to those of asspray-dried MMS (Figure S1), which reveals that the resultant $\alpha-\mathrm{Ni}(\mathrm{OH})_{2} \mathrm{MMS}$ was thermally stable to allow the removal of the F127 template. The SAXS pattern of heattreated MMS shows a peak centered at $0.384 \mathrm{~nm}^{-1}$, corresponding to a pore-to-pore periodicity of $16.4 \mathrm{~nm}$ (Fig. 4a). 

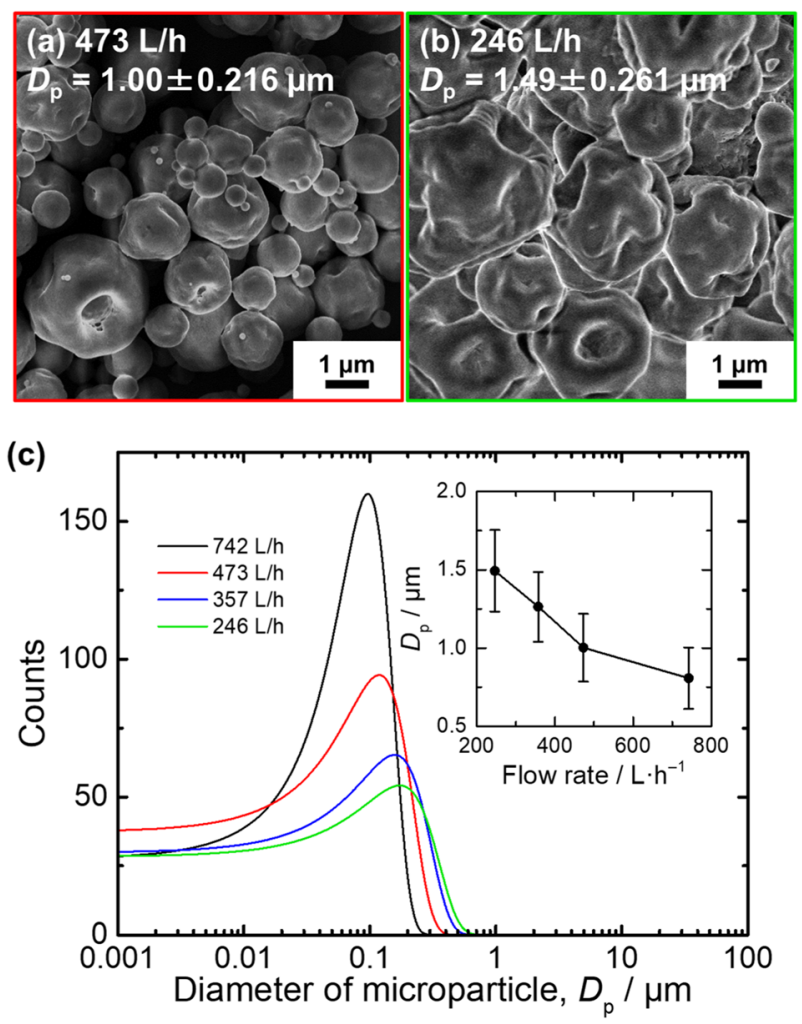

Fig. 6 SEM images of spray-dried powders prepared with a gas flow rate of a $473 \mathrm{~L} / \mathrm{h}$ and b $246 \mathrm{~L} / \mathrm{h}$. c Particle size distribution curves (calculated from histogram) of MMSs prepared with different gas flow rates. The condition of the solution before spray-drying was $t=5 \mathrm{~min}$ and $\mathrm{F} 127 / \mathrm{Ni}=0.005$ for all the samples. The diameters of 350 particles were averaged to estimate the $D_{\mathrm{p}}$ for each sample. Inset of $(\mathbf{c})$ is a relationship between $D_{\mathrm{p}}$ and flow rate

A TEM image of heat-treated MMS shows a wormhole-like mesoporous structure (Fig. 4b) [31], which confirms again that the meso-scale structure is robust enough toward the heat treatment. The present process is highly reproducible; the dilution of NBBs with $50 \mathrm{~mL}$ of water successfully quenched the growth and aggregation of NBBs, allowing the reproducible formation of MMSs by spray-drying. SEM images of spray-dried MMS prepared at different quenching times, $t_{\mathrm{q}}$, of $1 \mathrm{~min}$ and $3 \mathrm{~h}$ (duration time since diluting until spray-drying) are shown in Fig. 5a, b. Microspheres were formed independent of $t_{\mathrm{q}}$. SAXS patterns of spray-dried MMS prepared at $t_{\mathrm{q}}=1 \mathrm{~min}$ and $3 \mathrm{~h}$ showed a comparable peak, suggesting the formation of comparable mesoperiodicity. These results confirm that the diluting process could quench the growth of NBBs to form highly stable NBBs, which assures the reproducibility of the spray-drying step; microspheres with comparable size and shape in micrometer, with comparable meso-periodic structure in nanometer were formed irrespective of $t_{\mathrm{q}}$. Such a stable NBB colloid is highly preferable for a large-scale continuous synthesis by spray-drying.

\subsection{Control of diameter and shape of $a-N i(O H)_{2}$ mesoporous microspheres}

The controllability of diameter, size distribution, and shape of MMS are known to be important for its practical applications, for example, tuning the rheological property of a suspension toward specific applications [32, 33]. The gas flow rate of spray-drying was varied in the range of 246$742 \mathrm{~L} / \mathrm{h}$ to tune the diameter and shape of the microspheres. SEM images (Fig. 6a, b) show that $D_{\mathrm{p}}$ increased with decreasing flow rate. Generally, the diameter of the sprayed droplets increased with decreasing flow rate, which leads to the increase of the resultant $D_{\mathrm{p}}$. The spray-dried MMSs showed a dimple pattern on their surfaces. If the diameter of the sprayed droplets exceeds a critical value, the surface solidifies before the completion of evaporation of the inner solvent, and the dimple pattern forms as a result of buckling induced by the shrinkage of the inner part upon drying. Particle size distributions of MMSs prepared with different gas flow rates are shown in Fig. 6c. Along with the decrease of gas flow rate, $D_{\mathrm{p}}$ was indeed increased from $0.8 \pm 0.2 \mu \mathrm{m}$ to $1.5 \pm 0.3 \mu \mathrm{m}$ (Fig. $6 \mathrm{c}$ inset). In conclusion, a variety of MMSs with controllable diameter and surface structure can be prepared by simply changing the spray-drying conditions.

\subsection{Synthesis of Ni-M LDHs (M = Mn(II), Co(II), Cu(II), $\mathrm{Al}(\mathrm{III}), \mathrm{Fe}(\mathrm{III})$, and $\mathrm{Cr}(\mathrm{III}))$ mesoporous microspheres}

As described above, the reaction time $t$ and the F127/Ni ratio are essential parameters to obtain crystalline MMSs. The choice of carboxylic acid used as an additive is another important parameter to improve the dispersibility of NBBs. The systematic investigation revealed that using acrylic acid instead of glutaric acid is highly effective to prevent aggregation of growing NBBs during the massive consumption of $\mathrm{Ni}(\mathrm{II})$ ions. In the case of acrylic acid used, $96.2 \%$ of precursor $\mathrm{Ni}(\mathrm{II})$ ions were consumed at $t=60 \mathrm{~min}$ without involving gelation, which is a preferable condition for the preparation of crystalline mesoporous materials through the present NBB approach. The PXRD pattern of spray-dried MMS was assigned to acrylate-intercalated $\alpha-\mathrm{Ni}$ $(\mathrm{OH})_{2}$ (Fig. 7a) (lattice spacing: $12.3 \AA$ A) without segregation of other impurity phases [34]. The STEM image of NBBs used for spray-drying $(t=60 \mathrm{~min})$ is shown in Fig. $7 \mathrm{~b}$. $D_{\mathrm{NBB}}$ was $2.00 \mathrm{~nm}$, which is small enough to form F127templated mesoporous structures. The colloid of NBBs prepared with acrylic acid was spray-dried to prepare MMS. SEM and TEM observations of the spray-dried MMS after the heat treatment at $250{ }^{\circ} \mathrm{C}$ for $6 \mathrm{~h}$ reveals that the microspheres have a smooth surface while a templated 
Fig. 7 a PXRD pattern of spraydried MMS, $\mathbf{b}$ STEM image of NBBs before spray-drying, $\mathbf{c}$ SEM image, and d TEM image of heat-treated MMS prepared from the solution containing acrylic acid. The diameters of 100 particles were averaged to estimate $D_{\mathrm{NBB}}$
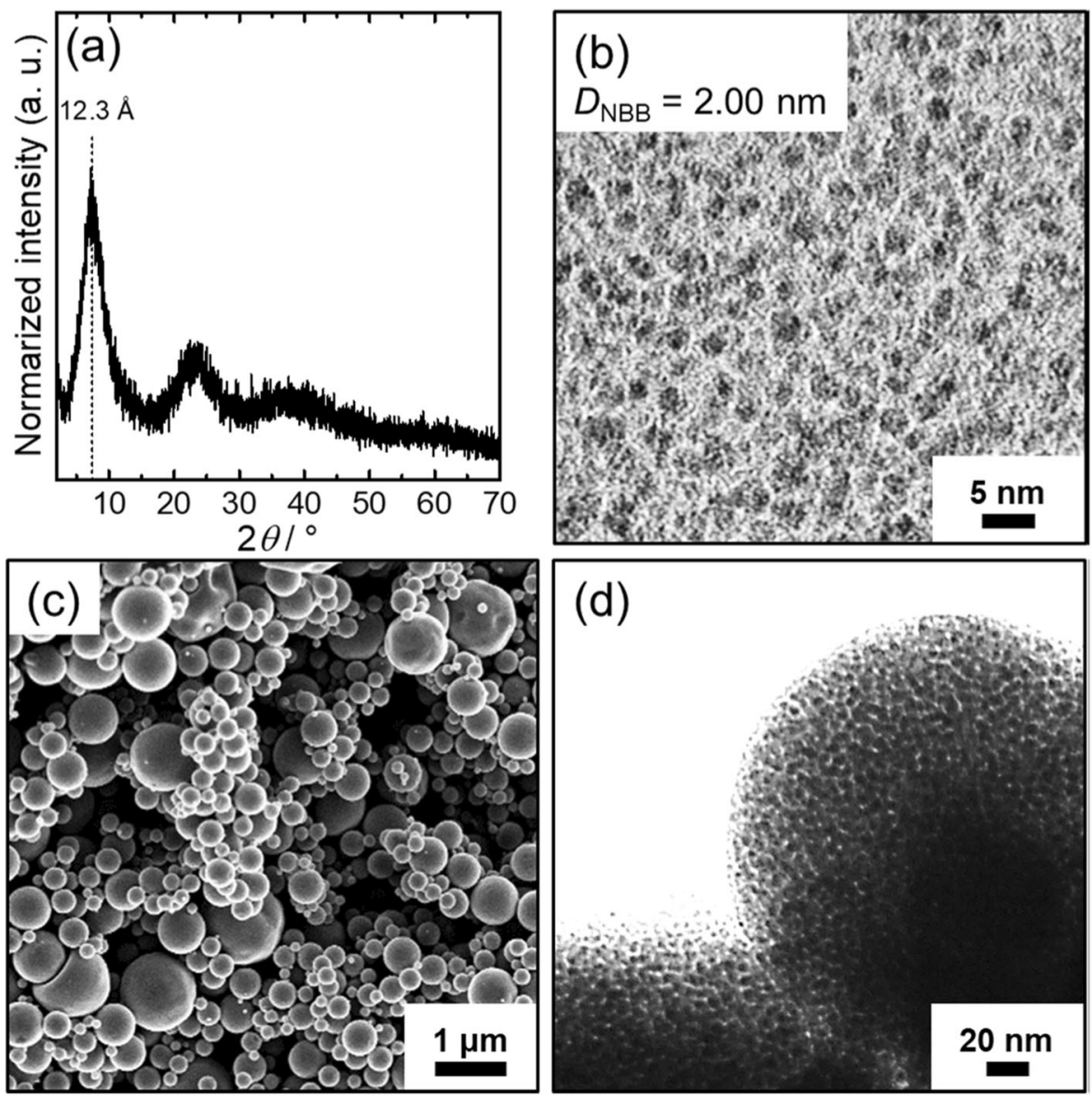

mesoporous structure was formed inside the microspheres (Fig. 7c, d).

The precursory nickel chloride was partially replaced with a metal chloride of a target element in order to tune the chemical composition of spray-dried MMSs. The PXRD patterns of spray-dried MMSs with various chemical compositions are shown in Fig. 8a. All of the patterns were comparable to that of acrylate-intercalated $\alpha-\mathrm{Ni}(\mathrm{OH})_{2}$, suggesting the formation of layered hydroxides. Figure 8b, c show STEM images of Ni-Co and Ni-Fe NBBs before spray-drying. Both of the NBBs exhibit a high homogeneity in diameter and shape, suggesting that metal cations are homogeneously distributed in a single particle rather than the segregation of respective hydroxide components in the nanometer scale. Indeed, it is known that the divalent metal ions of $\mathrm{Mn}, \mathrm{Co}$, and $\mathrm{Cu}$ form layered hydroxide phases similar to $\alpha-\mathrm{Ni}(\mathrm{OH})_{2}$, and they are able to form solid solutions [35]. Generally, the replacement of $\mathrm{Ni}(\mathrm{II})$ with a trivalent metal in the preparation step of Ni-based hydroxides results in the segregation of trivalent metal (oxy) hydroxide because solubility products of $\mathrm{M}$ (III) and $\mathrm{Ni}(\mathrm{II})$ hydroxides are considerably different $[36,37]$. On the other hand, the present Ni-M LDHs form without any apparent segregation of $\mathrm{M}(\mathrm{III})$ hydroxides, which is strongly suggested by a high homogeneity in diameter of NBBs for respective samples (Figure S2a-d). The chemical compositions obtained from STEM-EDS reveal that NBB contains $\mathrm{Ni}$ and substituted metal elements with a molar ratio of $\mathrm{Ni}$ : $\mathrm{M}=0.71-0.82: 0.29-0.18$ (Table S1). For all the systems, $D_{\mathrm{NBB}}$ was $2.05-3.24 \mathrm{~nm}$, which is small enough toward the formation of templated mesostructures. The macro- and mesostructures of heat-treated MMSs prepared from these various NBBs are shown in Fig. 8d-g and Figure S2e-1. The micrometer-scale spherical shape with dimple patterns was observed by SEM. TEM images revealed that the mesoporous structures formed for all the samples. These results confirm that the synthesized crystals successfully worked as NBB to form mesostructure together with the F127 template, and the obtained mesostructures were robust enough toward the heat treatment irrespective of the chemical composition. The chemical compositional versatility is important to improve and optimize the electrochemical, catalytic, and magnetic properties of the layered hydroxides [38-40].

In conclusion, the metal hydroxide MMSs with various diameter, surface structure, and chemical composition were successfully synthesized by epoxide-mediated alkalinization and spray-drying. It is interesting to remark that the control of the sol-gel condensation conditions, as well as the surface philicity, permits to yield NBBs with adequately 

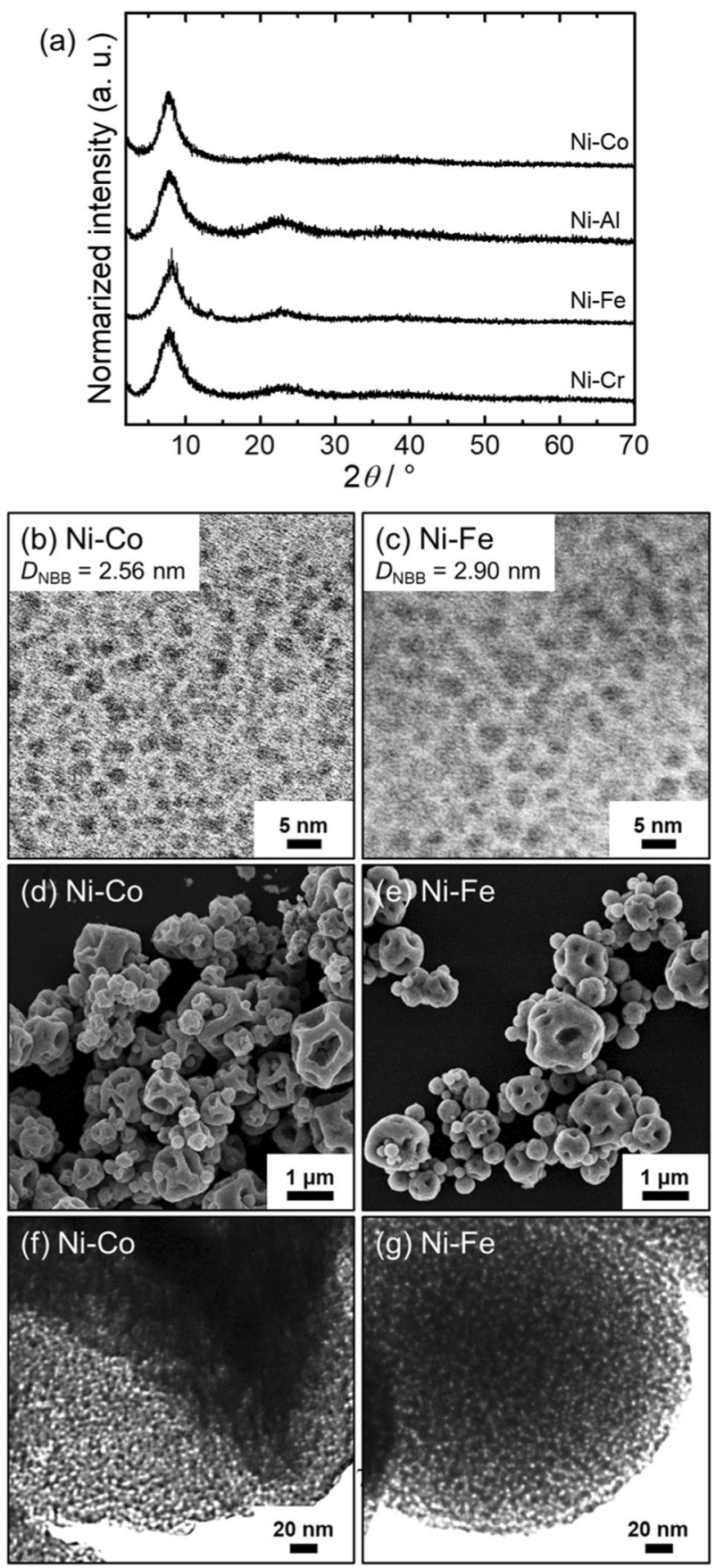

Fig. 8 a PXRD pattern of spray-dried MMSs, b, c STEM image of NBBs used for spray-drying, $\mathbf{d}, \mathbf{e}$ SEM images and $\mathbf{f}, \mathbf{g}$ TEM images of heat-treated MMSs of Ni-M (M = Co(II) and Fe(III)). The diameters of 100 particles were averaged to estimate $D_{\mathrm{NBB}}$

small sizes and interactions that generate self-assembled MMSs akin to those obtained in NBB-based mesoporous thin films [22]. An adequate understanding of these critical sizes and interactions can lead to the actual design of these complex materials with highly tailored porosity and wall structure [41].

\section{Conclusion}

Templated MMSs of nickel-based layered hydroxides were synthesized by spray-drying the NBBs, which were prepared through the epoxide-mediated alkalinization process in the presence of glutaric or acrylic acids. Reaction time and molar ratio, $\mathrm{F} 127 / \mathrm{Ni}$, were essential parameters to inhibit the formation of a coarse crystal and macroscopic separation between NBB and F127, allowing the successful formation of ordered MMS composed of $\alpha-\mathrm{Ni}(\mathrm{OH})_{2}$ NBBs. The diameter and surface texture of microspheres were controlled as $0.8 \pm$ $0.2-1.5 \pm 0.3 \mu \mathrm{m}$ and from smooth surface to dimple patterned surface with a reaction parameter of the gas flow rate during spray-drying. NBBs of various chemical compositions were prepared with a diameter of about $2-3 \mathrm{~nm}$ through the same alkalinization process by the partial replacement of nickel salt with target metal salts. Thus synthesized NBBs of various chemical compositions were successfully selfassembled into MMSs. Further understanding of these NBBs would open up the design of complex materials with highly tailored porosity and wall structure as well as high functionalities of layered nanocrystals.

Acknowledgements Strategic Young Researcher Overseas Visits Program for Accelerating Brain Circulation from JSPS is gratefully acknowledged. The present work was partially supported by JSPS KAKENHI, JSPS bilateral program, LNLS proposal SAXS1 18927, ANPCyT (PICT 2012-2087 and 2015-3526), UBACyT (20020130100610BA), Hitachi Metals Materials Science Foundation, The Sumitomo Foundation, and Izumi Science and Technology Foundation. We thank Mr. J. Daniels and Mr. S. M. Nikka for the helpful discussions.

\section{Compliance with ethical standards}

Conflict of interest The authors declare that they have no conflict of interest.

\section{References}

1. Arcos D, López-Noriega A, Ruiz-Hernández E, Terasaki O, Vallet-Regí M (2009) Chem Mater 21:1000-1009

2. Son HY, Kim KR, Lee JB, Kim THL, Jang J, Kim SJ, Yoon MS, Kim JW, Nam YS (2017) Sci Rep 7:14728

3. Liu Y, Lan K, Bagabas AA, Zhang P, Gao W, Wang J, Sun Z, Fan J, Elzatahry AA, Zhao D (2016) Small 12:860-867

4. Hou S, Li X, Wang H, Wang M, Zhang Y, Chi Y, Zhao Z (2017) RSC Adv 7:51993-52000

5. Zhou J, Wang Y, Wang J, Qiao W, Long D, Ling L (2016) J Colloid Interface Sci 462:200-207

6. Hassan MS, Lau RWM (2009) AAPS PharmSciTech 10:12521262.

7. Liu Y, Shen D, Chen G, Elzatahry AA, Pal M, Zhu H, Wu L, Lin J, Al-Dahyan D, Li W, Zhao D (2017) Adv Mater 29:1702274

8. Cirujano FG, Luz I, Soukri M, Goethem CV, Vankelecom IFJ, Lail M, Vos DED (2017) Angew Chem Int Ed 56:13302-13306

9. Meng FL, Wang ZL, Zhong HX, Wang J, Yan JM, Zhang XB (2016) Adv Mater 28:7948-7955 
10. Tian M, Sun Y, Zhang CJ, Wang J, Qiao W, Ling L, Long D (2017) J Power Sources 364:182-190

11. Shi Y, Wan Y, Zhao D (2011) Chem Soc Rev 40:3854-3878

12. Gu D, Schüth F (2014) Chem Soc Rev 43:313-344

13. Griin M, Lauer I, Unger KK (1997) Adv Mater 9:254-257

14. Lu Y, Fan H, Stump A, Ward TL, Rieker T, Brinker CJ (1999) Nature 398:223-226

15. Grosso D, Soler-Illia GJAA, Crepaldi EL, Charleux B, Sanchez C (2003) Adv Funct Mater 13:37-42

16. Sanchez C, Soler-Illia GJAA, Ribot F, Lalot T, Mayer CR, Cabuil V (2001) Chem Mater 13:3061-3082

17. Fan J, Boettcher SW, Stucky GD (2006) Chem Mater 18:63916396

18. Boettcher SW, Fan J, Tsung CK, Shi Q, Stucky GD (2007) Acc Chem Res 40:784-792

19. Boissiere C, Grosso D, Chaumonnot A, Nicole L, Sanchez C (2010) Adv Mater 23:599-623

20. Gash AE, Tillotson TM, Satcher JH, Poco JF, Hrubesh LW, Simpson RL (2001) Chem Mater 13:999-1007

21. Tokudome Y, Tarutani N, Nakanishi K, Takahashi M (2013) J Mater Chem A 1:7702-7708

22. Tarutani N, Tokudome Y, Jobbágy M, Viva FA, Soler-Illia GJAA, Takahashi M (2016) Chem Mater 28:5606-5610

23. Wong MS, Jeng ES, Ying JY (2001) Nano Lett 1:637-642

24. Rauda IE, Buonsanti R, Saldarriaga-Lopez LC, Benjauthrit K, Schelhas LT, Stefik M, Augustyn V, Ko J, Dunn B, Wiesner U, Milliron DJ, Tolbert SH (2012) ACS Nano 6:6386-6399

25. Warren SC, Messina LC, Slaughter LS, Kamperman M, Zhou Q, Gruner SM, DiSalvo FJ, Wiesner U (2008) Science 320:17481752
26. Soler-Illia GJAA, Scolan E, Louis A, Albouyb PA, Sanchez C (2001) New J Chem 25:156-165

27. Innocenzi P, Luca Malfatti L, Piccinini M, Marcelli A (2010) J Phys Chem A 114:304-308

28. Zhao D, Feng J, Huo Q, Melosh N, Fredrickson GH, Chmelka BF, Stucky GD (1998) Science 279:548-552

29. Soler-Illia GJAA, Sanchez C, Lebeau B, Patarin J (2002) Chem Rev 102:4093-4138

30. Pauly TR, Liu Y, Pinnavaia TJ, Billinge SJL, Rieker TP (1999) J Am Chem Soc 121:8835-8842

31. Kodas TT, Hampden-Smith MJ (1999) Aerosol processing of materials. John Wiley \& Sons, New York

32. Olhero SM, Ferreira JMF (2004) Powder Technol 139:69-75

33. Mueller S, Llewellin EW, Mader HM (2011) Geophys Res Lett 38:L13316

34. Vaysse C, Guerlou-Demourgues L, Duguet E, Delmas C (2003) Inorg Chem 42:4559-4567

35. Arizaga GGC, Satyanarayana KG, Wypych F (2007) Solid State Ion 178:1143-1162

36. Boclair JW, Braterman PS (1999) Chem Mater 11:298-302

37. Tarutani N, Tokudome Y, Fukui M, Nakanishi K, Takahashi M (2015) RSC Adv 5:57187-57192

38. Nguyen T, Boudard M, Carmezim MJ, Montemor MF (2017) Energy 126:208-216

39. Song F, Hu X (2014) Nat Commun 5:4477

40. Abellán G, Carrasco JA, Coronado E (2013) Inorg Chem 52:7828-7830

41. Tang Q, Angelomé PC, Soler-Illia GJAA, Müller M (2017) Phys Chem Chem Phys 19:28249-28262 